predictor of treatment failure at 1yr among CZP-treated RA pts was high; $88.8 \%$ of pts identified as non-responders at Wk12 will represent a treatment failure at 1yr. Simple tools such as CDAl, assessed during routine consultations, may be reliable markers to predict treatment failure without need for complementary biological tests.

References:

[1] Keystone EC. J Rheumatol 2011;38:990-6.

[2] Curtis JR. Arth Care Res 2012;64:658-67.

[3] van der Heijde D. J Rheumatol 2012;39:1326-33.

Acknowledgements: This study was funded by UCB Pharma. We thank the patients and their caregivers in addition to the investigators and their teams who contributed to this study. We also thank Isabelle Bru (UCB Pharma) who helped conduct the ECLAIR study. Editorial services were provided by Costello Medical Consulting.

Disclosure of Interest: A. Saraux Consultant for: UCB Pharma, R. M. Flipo Consultant for: UCB Pharma, F. Fagnani Consultant for: UCB Pharma, J. Massol: None declared, B. Combe Grant/research support from: Merck Pfizer Inc, RocheChugai, Consultant for: Merck, Pfizer, Roche-Chugai, UCB Pharma, Bristol-Myers Squibb, Celgene, Eli Lilly, Speakers bureau: Merck, Pfizer, Roche-Chugai, UCB Pharma, Bristol-Myers Squibb, Celgene, Eli Lilly, Novartis, P. Huot-Marchand: None declared, J. M. Joubert Employee of: UCB Pharma, J. Dunkel Employee of: UCB Pharma, G. Cukierman Employee of: UCB Pharma

DOI: 10.1136/annrheumdis-2017-eular.1974

\section{SAT0051 CITRULLINATION OF ADENOSINE DEAMINASE ISOFORMS IN RHEUMATOID ARTHRITIS}

S. Sharoyan ${ }^{1}$, L. Karapetyan ${ }^{1}$, R. Harutyunyan ${ }^{2}$, S. Mardanyan ${ }^{1}$, A. Antonyan ${ }^{1}$ ${ }^{1}$ H.Ch. Buniatian Institute of Biochemistry of Armenian NAS; " "Yerevan" Medical Center, Yerevan, Armenia

Background: One of the most important discoveries in rheumatology is the characterization of citrulline containing auto-antigens [1]. The identification of citrullinated proteins as auto-antigens and the development of new assay based on the detection of anti-citrullinated protein antibodies (ACPAs) become a breakthrough in the diagnosis and treatment of rheumatoid arthritis (RA). Mitsui and coauthors in vitro identified adenosine deaminase (ADA) as an ACPA antigen [2]. Earlier we have reported the enhance of ADA activity in synovial fluids (SFs) of RA patients [3].This increasing was in correlation with the ratio of small isoenzyme (SADA) to the large (LADA) [4].The comparison of citrullination states of SADA and LADA can be a clue for understanding the mechanism of SADA/LADA increase in RA, which is important both in diagnosis and treatment of the disease.

Objectives: The objectives of this study were a) to separate SADA and LADA isoforms from SFs of RA patients and $b$ ) to compare their citrullination degree. Methods: The SADA and LADA isoforms from SFs of RA patients were separated and purified using gel-filtration and ion-exchange chromatography [4]. The citrullination degree of the isoforms was measured in the colorimetric assay with diacetylmonoxime (DAMO) [6] using the absorbance at $530 \mathrm{~nm}$ and free L-citrulline as a standard.

Results: The SF samples of 20 RA patients with initial ADA activity in the range 35-190 IU/L were used. Earlier we demonstrated a negligible level of SADA at initial ADA lower of this interval. In the samples with medium initial activity (35-55 IU/L), SADA/LADA ratio was $\approx 1 / 2$. In those with high ADA activity (100-190 IU/L) this ratio was $\approx 4$. The separation and purification of LADA from 10 SFs revealed that it is not citrullinated in any case. In SADA from SFs with medium ADA activity, we failed to register the citrullination. In SADA from SFs with the initial ADA activity $\geq 100 \mathrm{IU} / \mathrm{L}$, the significant citrullination $(\approx 0.6 \mu \mathrm{mol} / \mathrm{mg}$ of protein) was registered.

Conclusions: The obtained results evidence that SADA from SFs with high ADA activity can serve as new citrulline containing ACPA antigen. This finding can be a base of developing new strategy (e.g. seeking specific inhibitors) for treatment of RA patients because citrullination enhances the ADA activity [2], hampering the increase of adenosine by methotrexate.

References:

[1] vanVenrooij WJ, van Beers JJ, Pruijn GJ. Anti-CCP Antibody, a Marker for the Early Detection of Rheumatoid Arthritis. Ann NY Acad Sci.1143:268-85, 2008.

[2] Mitsui H, Arito M, Sato T, Yokoyama MK, Suematsu N, et al. Novel anticitrullinated peptide autoantibodies identified by proteomics with in vitro citrullinated proteins in patients with rheumatoid arthritis. Inflammation and Regeneration 33:121-30, 2013.

[3] Antonyan A, Sharoyan S, Haroyan A, Harutyunyan R, Mardanyan S. Adenosine Deaminase activity in synovial fluid at arthritis. Proceedings of YSU. Chemistry and Biology 3:28-32, 2013

[4] Antonyan A, Sharoyan S, Haroyan A, Harutyunyan R, Mardanyan S. Adenosine Deaminase Isoforms in synovial fluid at Rheumatoid arthritis. Proceedings of YSU. Chemistry and Biology 2:54-57, 2014.

[5] Boyde TR, Rahmatullah M. Optimization of conditions for the colorimetric determination of citrulline, using diacetylmonoxime. Anal Biochem 107:424$431,1980$.

Disclosure of Interest: None declared

DOI: 10.1136/annrheumdis-2017-eular.1433

\section{SAT0052 HIGH CHANCE OF COMPREHENSIVE DISEASE CONTROL (CDC) IN VERY EARLY AND NORMAL WEIGHT RHEUMATOID ARTHRITIS PATIENTS TREATED ACCORDING TO THE TREAT TO TARGET STRATEGY}

A.L. Fedele, L. Petricca, B. Tolusso, S. Alivernini, C. Di Mario, G. Di Sante, G. Ferraccioli, E. Gremese. Institute of Rheumatology, Fondazione Policlinico Universitario A. Gemelli, Rome, Italy

Background: The ultimate goal for Rheumatoid Arthritis (RA) management is the simultaneous achievement of all clinical, functional and structural efficacy, i.e. comprehensive disease control (CDC) [1].

Objectives: To evaluate the effective chance and the consequences of $\mathrm{CDC}$ achievement in real world practice of Early Arthritis Clinic (EAC).

Methods: A total of 349 early rheumatoid arthritis (ERA) patients with a disease duration of less than 12 months were enrolled in the study. ERA patients fulfilled the 2010 ACR criteria for RA and were followed according to the treat-to-target strategy. Subjects with symptom duration less than 3 months were defined as having "very early RA" (VERA). The mean follow-up (FU) was $38.2 \pm 32.8$ months. At baseline, and every three months, the ACR/EULAR core data set variables were recorded. At baseline and every year hand and foot radiographs were examined according to modified Total Sharp score (mTSS). At each visit, clinical improvement and remission were evaluated according to EULAR criteria. The achievement of CDC (28-joint Disease Activity Score using $C$ reactive protein $<2.6$, Health Assessment Questionnaire $<0.5$ and change from baseline in $\mathrm{mTSS}$ $\leq 0.5$ ) was assessed every year of follow-up.

Results: At the twelfth month of FU 148 (42.4\%) ERA patients achieved CDC, while at the time of last FU $228(65.3 \%)$ subjects reached this target.

Patients achieving CDC at the 12th month of FU were younger $(p=0.05)$, in higher percentage male $(p=0.004)$, and with a normal weight (body mass index, BMI $<25)(p=0.003)$ and had a shorter disease duration, comprising a greater number of VERA $(p=0.01)$, compared to subjects not achieving disease control. There were no differences concerning autoantibody positivity and presence of erosions at onset between the two analyzed cohorts. Adjusting the analysis for age, the variables that arose as independent predictors of CDC at the 12th month of FU were a disease duration less than 3 months [OR $(95 \% \mathrm{Cl}): 1.97(1.23-3.14)]$ and a normal BMI [OR (95\% Cl): 2.05 (1.32-3.21)].

In our cohort, $105(30.1 \%)$ ERA patients were treated with biological disease modifying anti-rheumatic drugs (bDMARDs) over time. Biotechnological therapy was less frequently started by subjects in CDC, both after 12 months $(p=0.003)$ and at the time of last FU $(p<0.0001)$. At the multivariate analysis, not achieving $\mathrm{CDC}$ at the 12th month of FU [OR (95\% Cl): 2.69 (1.59-4.57)] and a BMI $\geq 25$ [OR $(95 \% \mathrm{Cl}): 2.05(1.23-3.42)]$ were the variables significantly associated to bDMARD therapy over time.

Conclusions: The simultaneous achievement of symptom control, inhibition of radiographic progression and normalization of function, is a feasible target in real word EAC. Having a VERA and a normal weight are associated to a high chance of "deep" remission.

References:

[1] Emery P, et al. Ann Rheum Dis 2015; 74: 2165-2174.

Disclosure of Interest: None declared

DOI: 10.1136/annrheumdis-2017-eular.5496

\section{SAT0053 THE INCIDENT IMMUNOLOGICAL STATUS PREDICTS DRUG-FREE DISEASE FLARE IN RHEUMATOID ARTHRITIS PATIENTS ACHIEVING STRINGENT CLINICAL AND ULTRASONOGRAPHIC CONTROL OF THE PERIPHERAL INFLAMMATORY PROCESS}

A. Manzo, S. Bugatti, F. Benaglio, B. Vitolo, G. Sakellariou, R. Caporali, C. Montecucco. Rheumatology and Translational Immunology Research Laboratories (LaRIT), Division of Rheumatology, IRCCS Policlinico San Matteo Foundation/University of Pavia, Pavia, Italy

Background: The development of predictive tools to evaluate health risks and design personalized health plans in patients with rheumatoid arthritis (RA) achieving remission still represents a major unmet need. In this perspective, the relative weight of clinical, ultrasound and immunological assessment of disease characteristics for predicting recurrence of the inflammatory process under drug-free conditions remains unclear.

Objectives: To investigate the predictive value of baseline clinical remission stringency, synovial power Doppler (PD) ultrasound indices and the incident autoimmune status, as predictors of flare under drug-free conditions after a DAS28-driven treatment strategy with methotrexate (MTX) in early RA.

Methods: 85 RA patients achieving stable remission and candidate to MTX withdrawal were recruited according to the following criteria: 1) introduction of MTX within 12 months from symptoms' onset, 2) at least 24 months of MTX treatment with a DAS28-driven protocol targeting low disease activity (LDA), 3) DAS28 $<2.6$ for $>6$ months in the absence of corticosteroids. Following treatment suspension, patients were monitored at three months' intervals across 24 months through clinical, ultrasound (hands-feet-axillary lymph nodes), radiographic and immunologic screenings (ACPA-RF status, CXCL13 circulating levels [1-2] and FACS analysis for quantification of Ki67+/regulatory T-B cell subsets). Treatment was re-introduced in case of DAS28 $\geq 3.2$ or stable LDA. 
Results: At baseline, $84 \%$ of the patients were in remission according to the SDAI $(<3,3)$ with $44 \%$ of the cases showing SDAI remission and absence of $\mathrm{PD}$ signal in hands and feet $(\mathrm{SDAl}<3,3$ and $\mathrm{PD}=0)$. Despite stringent remission, $48 \%$ of the patients showed an episode of flare during follow-up with a peak incidence between 6 and 9 months after drug withdrawal. With the exception of a mild protective role of SDAI remission, none of the investigated clinical and ultrasound parameters (alone or in combination) showed a significant impact on clinical evolution across 24 months. ACPA IgG levels showed instead a strong, inflammation-independent predictive value for disease recurrence, an observation that was confirmed in the overall cohort (HR: 3.39 [1.7-6.64], $p=0.0006$, Cox regression) and, invariably, across progressive clinical and/or ultrasound remission thresholds (SDAI remission, SDAI remission- $P D=0$ ). Sub-analyses focused on short-term events (0-6 months after DMARDs withdrawal), identified the systemic level of CXCL13 at baseline as the strongest predictor of early disease recurrence in ACPA lgG positive individuals.

Conclusions: The systemic immuno-type of patients in remission is the major determinant of drug-free disease recurrence, over and above drug-induced achievement of stringent clinical and ultrasonographic control of the peripheral inflammatory process.

\section{References:}

[1] Meeuwisse CM et al. Identification of CXCL13 as a marker for rheumatoid arthritis outcome using an in silico model of the rheumatic joint. Arthritis Rheum 2011; 63: 1265-73.

[2] Havenar-Daughton C et al. CXCL13 is a plasma biomarker of germinal center activity. Proc Natl Acad Sci U S A 2016; 113: 2702-7.

Disclosure of Interest: None declared

DOI: 10.1136/annrheumdis-2017-eular.6958

\section{SAT0054 RISK FACTORS FOR ACUTE EXACERBATION OF RHEUMATOID ARTHRITIS-ASSOCIATED INTERSTITIAL PNEUMONIA}

A. Yashima, H. Yamashita, R. Kamei, K. Suga, M. Nakano, S. Yamada, Y. Takahashi, H. Kaneko. Division of Rheumatic Diseases, National Center for Global Health and Medicine, Tokyo, Japan

Background: Acute exacerbation ( $\mathrm{AE}$ ) is recently recognized as deterioration of respiratory status in idiopathic pulmonary fibrosis. It is reported that $A E$ also occurs in other interstitial lung diseases (ILD) such as collagen vascular diseases associated ILD (CVD-ILD). However, the characteristics and risk factors of AE in CVD-ILD are not clearly identified.

Objectives: To clarify the characteristics of patients with rheumatoid arthritisassociated interstitial pneumonia (RA-IP) and to investigate the risk factors associated with $A E$ and its survival of RA-IP.

Methods: We examined the clinical features of 60 RA-IP patients admitted to our hospital between July 2010 and September 2016. We compared the characteristics between patients who developed $A E$ (AE group) and those who didn't (non-AE group), and between patients who survived after AE (alive group) and those who died after AE (dead group), and identified variables significantly associated with $\mathrm{AE}$ occurrence and survival using Cox hazards analyses.

Results: Thirty-six (60\%) were female. Twenty-two (36.7\%) developed AE and seven of them $(11.7 \%)$ died with the mean follow-up period of 2.7 years. The mean age at $R A$ diagnosis was $61.1 \pm 16.3$ years in $A E$ group and $61.5 \pm 13.1$ years in non-AE group. Sex, smoking habit and high-resolution computed tomography (HRCT) pattern were not significantly different between two groups. Although there was no significant difference, more patients in $\mathrm{AE}$ group received methotrexate (MTX) treatment than those in non-AE group ( $40.9 \%$ vs. $18.9 \%, p=0.08)$, and MTX use was significantly associated with occurrence of $\mathrm{AE}$ in a Cox hazard analysis (Hazard ratio $[\mathrm{HR}] 1.09,95 \%$ confidence interval $[\mathrm{Cl}]$ 1.01-1.18). Further, age (median 70 vs. 82 years, $p=0.002$ ) and matrix metalloproteinase-3 (MMP-3) level (median 84.8 vs. $205.6 \mathrm{ng} / \mathrm{mL}, p=0.03$ ) on admission were significantly higher in dead group than in alive group. Univariate analyses revealed that age $\geqq 75$ years (HR 10.53, 95\% Cl 1.26-88.15), MMP- $3 \geqq 200 \mathrm{ng} / \mathrm{mL}(\mathrm{HR} 15.58,95 \%$ $\mathrm{Cl} 1.38-175.8)$, and $3 \mathrm{~L}$ or more oxygen use (HR $8.46,95 \% \mathrm{Cl} 1.02-70.49)$ on admission were associated with death (Table 1).

Table 1. Risk factors for AE mortality based on univariate Cox hazard analyses

\begin{tabular}{lccc}
\hline & $\mathrm{HR}$ & $95 \% \mathrm{Cl}$ & $p$ value \\
\hline Age $\geq 75$ years & 1.19 & 1.05 to 1.36 & 0.008 \\
Sex, male & 1.65 & 0.37 to 7.41 & 0.51 \\
$\mathrm{HRCT}$, UIP pattern & 3.82 & 0.74 to 19.8 & 0.11 \\
$\mathrm{KL}-6 \geq 700 \mathrm{U} . \mathrm{mL}$ & 1.32 & 0.24 to 7.22 & 0.75 \\
$\mathrm{LDH} \geq 400 \mathrm{IU} / \mathrm{L}$ & 0.40 & 0.05 to 3.32 & 0.40 \\
$\mathrm{MMP}-3 \geq 200 \mathrm{ng} / \mathrm{mL}$ & 15.58 & 1.38 to 175.80 & 0.03 \\
$\mathrm{O}_{2} \geq 3 \mathrm{~L}$ & 9.46 & 1.02 to 70.49 & 0.05 \\
\hline
\end{tabular}

UIP, usual interstitial pneumonia; KL-6, Krebs von den Lungen-6; LDH, lactate dehydrogenase.

Conclusions: Our data suggest that MTX use relates to the occurrence of AE, and age, MMP-3 level, and oxygen volume on admission relate to AE survival in patients with RA-IP.

\section{References:}

[1] Hozumi H, Nakamura Y, Johkoh T, et al. BMJ Open 2013; 3: e003132.

[2] Suda T, Kaida Y, Nakamura Y, et al. Respiratory Medicine 2009; 103: 846-853. Disclosure of Interest: None declared
DOI: 10.1136/annrheumdis-2017-eular.2683

\section{SAT0055 BARICITINIB SHOWED RAPID AND GREATER REDUCTION IN PAIN COMPARED TO ADALIMUMAB OR PLACEBO IN PATIENTS WITH RHEUMATOID ARTHRITIS}

P. Taylor $^{1}$, B. Zhu ${ }^{2}$, C. Gaich ${ }^{2}$, X. Zhang ${ }^{2}$, A.M. DeLozier ${ }^{2}$, D. Schlichting ${ }^{2}$, H. Patel ${ }^{2}$, F. Durand ${ }^{2}$, B. Fautrel ${ }^{3}$. ${ }^{1}$ University of Oxford, Oxford, United Kingdom; ${ }^{2}$ Eli Lilly and Company, Indianapolis, United States; ${ }^{3}$ University Pierre et Marie Curie, Paris, France

Background: A rapid and meaningful reduction in pain is important to quality of life in patients (pts) with rheumatoid arthritis (RA). Baricitinib (bari) is a selective inhibitor of Janus kinase (JAK)1/JAK 2 in development for pts with active RA. ${ }^{1}$

Objectives: To evaluate the effect of bari treatment on pain reduction compared to adalimumab (ADA) or placebo (PBO) in pts with inadequate response to methotrexate (MTX) or biologic disease-modifying antirheumatic drugs (bDMARDs).

Methods: In RA-BEAM (NCT01710358), 1305 patients with inadequate response to MTX were randomised 3:3:2 to $\mathrm{PBO} Q D$, bari $4 \mathrm{mg}$ once daily (QD), or ADA 40 mg biweekly. ${ }^{2}$ In RA-BEACON (NCT01721044), 527 pts with inadequate response or intolerance to bDMARDs were randomised $1: 1: 1$ to PBO or bari (2 or $4 \mathrm{mg}$ ) QD. ${ }^{3}$ This post-hoc analysis reports the pts' assessment of pain using a visual analogue scale (VAS, range: 0 to $100 \mathrm{~mm}$ ). The proportion of pts who achieved pain improvement of $\geq 30 \%, \geq 50 \%$, and $\geq 70 \%$ of their baseline pain at $1,2,4,8,12,16,20$, and 24 weeks of treatment were compared between treatment groups using logistic models adjusted for geographic region, baseline pain score, baseline joint erosion status (RA-BEAM only), and history of bDMARD at screening (RA-BEACON only). Missing data were imputed using modified last observation carried forward.

Results: Mean baseline pain scores were 60, 62, and 61 for PBO, bari $4 \mathrm{mg}$, and ADA, respectively, in RA-BEAM and 65, 62, and 66 for PBO, bari $2 \mathrm{mg}$, and bari $4 \mathrm{mg}$, respectively, in RA-BEACON. A significantly greater proportion of pts treated with bari $4 \mathrm{mg}$ achieved $\geq 30 \%$ and $\geq 50 \%$ pain improvement as early as week 1 compared to PBO (both studies) and as early as week 4 compared to ADA (RA-BEAM) (Table). A significant pain improvement of $\geq 70 \%$ was achieved at week 12 for pts treated with bari $4 \mathrm{mg}$ compared to PBO (both studies) and ADA (RA-BEAM). Pain improvement of $>30 \%, \geq 50 \%$, and $>70 \%$ with bari 2 mg was significant compared to PBO by week 12 (RA-BEACON). Significant improvements in pain for bari vs PBO and bari vs ADA were sustained through week 24.

Table 1. Percent Pain Improvement in RA-BEAM and RA-BEACON

\begin{tabular}{|c|c|c|c|c|c|c|}
\hline & \multicolumn{3}{|c|}{ RA-BEAM } & \multicolumn{3}{|c|}{ RA-BEACON } \\
\hline & $\begin{array}{c}\text { PBO } \\
(\mathrm{N}=488)\end{array}$ & $\begin{array}{l}\text { Bari } 4 \mathrm{mg} \\
(\mathrm{N}=487)\end{array}$ & $\begin{array}{c}\text { ADA } \\
(\mathrm{N}=330)\end{array}$ & $\begin{array}{c}\text { PBO } \\
(\mathrm{N}=176)\end{array}$ & $\begin{array}{l}\text { Bari } 2 \mathrm{mg} \\
(\mathrm{N}=174)\end{array}$ & $\begin{array}{c}\text { Bari } 4 \mathrm{mg} \\
(\mathrm{N}=177)\end{array}$ \\
\hline \multicolumn{7}{|c|}{ Pain Improvement $\geq 30 \%$} \\
\hline Week 1 & 27 & $48^{\star \star \star}$ & $47^{\star \star \star}$ & 20 & 25 & $32^{\star \star}$ \\
\hline Week 4 & 37 & $67^{\star \star \star \dagger}$ & $60^{\star \star \star}$ & 29 & 38 & $50^{\star \star \star}$ \\
\hline Week 12 & 47 & $73^{\star \star \star \dagger}$ & $64^{\star \star \star}$ & 31 & $43^{\star}$ & $58^{\star \star \star}$ \\
\hline Week 24 & 49 & $74^{\star \star \star}$ & $69^{\star \star \star}$ & 34 & $44^{*}$ & $57^{\star \star \star}$ \\
\hline \multicolumn{7}{|c|}{ Pain Improvement $\geq 50 \%$} \\
\hline Week 1 & 13 & $26^{\star \star \star}$ & $28^{\star \star \star}$ & 6 & 9 & $17^{\star \star}$ \\
\hline Week 4 & 22 & $48^{\star \star \star \ddagger}$ & $37^{\star \star \star}$ & 15 & $25^{\star}$ & $30^{\star \star \star}$ \\
\hline Week 12 & 31 & $57^{\star \star \star \star 十}$ & $49^{\star \star \star}$ & 17 & $31^{\star *}$ & $35^{\star \star \star}$ \\
\hline Week 24 & 32 & $61^{\star \star \star \star}$ & $52^{\star \star \star}$ & 20 & $32^{\star \star}$ & $45^{\star \star \star}$ \\
\hline \multicolumn{7}{|c|}{ Pain Improvement $\geq 70 \%$} \\
\hline Week 1 & 4 & $12^{\star \star \star}$ & $11^{\star \star \star}$ & 2 & 3 & 6 \\
\hline Week 4 & 8 & $26^{\star \star \star}$ & $21^{\star \star \star}$ & 6 & 11 & $14^{\star}$ \\
\hline Week 12 & 14 & $37^{\star \star \star \star}$ & $28^{\star \star \star}$ & 7 & $19^{\star \star \star}$ & $18^{\star \star}$ \\
\hline Week 24 & 16 & $41^{\star \star \star \ddagger}$ & $32^{\star \star \star}$ & 9 & $22^{\star \star \star}$ & $29^{\star \star \star}$ \\
\hline
\end{tabular}

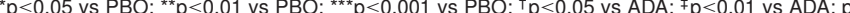
values based on logistic regression model. $A D A=$ adalimumab; $B$ ari = baricitinib; $P B O=$ placebo

Conclusions: Bari-treated pts reported significantly greater and more rapid reductions in pain severity as measured by the pain VAS compared to PBO or ADA; improvements were sustained through 24 weeks. The results were similar regardless of the pt population.

References:

[1] Fridman JS, et al. J Immunol 2010;184:5298-307.

[2] Taylor PC, et al. Arthritis Rheumatol 2015;67 (suppl 10):abstr 2L.

[3] Genovese MC, et al. N Engl J Med 2016;374:1243-52.

Disclosure of Interest: P. Taylor Grant/research support from: AbbVie, Bristol Myers Squibb, Celgene, Eli Lilly and Company, Galapagos, GlaxoSmithKline, Merck, Pfizer, UCB, Biogen, Sandoz and Janssen., Consultant for: AbbVie, Bristol Myers Squibb, Celgene, Eli Lilly and Company, Galapagos, GlaxoSmithKline, Merck, Pfizer, UCB, Biogen, Sandoz and Janssen., B. Zhu Employee of: Eli Lilly and Company, C. Gaich Employee of: Eli Lilly and Company, X. Zhang Employee of: Eli Lilly and Company, A. DeLozier Employee of: Eli Lilly and Company, D. Schlichting Employee of: Eli Lilly and Company, H. Patel: None declared, F. Durand: None declared, B. Fautrel Consultant for: AbbVle, Biogen, BMS, Celgene, Hospira, Janssen, Lilly, Novartis, Pfizer, Roche, SOBI pharma, UCB

DOI: 10.1136/annrheumdis-2017-eular.1346 